\title{
Engineering nanoparticles for targeting rheumatoid arthritis: Past, present, and future trends
}

\author{
Isabel Matos Oliveira ${ }^{1,2}$, Cristiana Gonçalves ${ }^{1,2}$, Rui Luís Reis ${ }^{1,2,3}$, and Joaquim Miguel Oliveira ${ }^{1,2,3}(\varangle)$ \\ '3B's Research Group - Biomaterials, Biodegradables, and Biomimetics, Headquarters of the European Institute of Excellence on \\ Tissue Engineering and Regenerative Medicine, AvePark, 4805-017 Barco, Guimarães, Portugal \\ ${ }^{2}$ ICVS/3B's-PT Government Associate Laboratory, University of Minho, Campus de Gualtar, 4710-057 Braga, Portugal \\ ${ }^{3}$ The Discoveries Centre for Regenerative and Precision Medicine, Headquarters at University of Minho, Avepark, 4805-017 Barco, \\ Guimarães, Portugal
}

Received: 26 January 2018

Revised: 8 April 2018

Accepted: 10 April 2018

(C) Tsinghua University Press and Springer-Verlag GmbH Germany, part of Springer Nature 2018

\section{KEYWORDS}

nanoparticles, liposomes, dendrimers, rheumatoid arthritis

\begin{abstract}
Rheumatoid arthritis (RA) is a chronic inflammatory disease characterized by synovial joint inflammation and cartilage and bone tissue destruction. Although there exist some treatment strategies for RA, they are not completely safe and effective. Therefore, it is important to develop and test new drugs for RA that specifically target inflamed/swollen joints and simultaneously attenuate other possible damages to healthy tissues. Nanotechnology can be a good alternative to consider when envisioning precise medication for treating RA. Through the use of nanoparticles, it is possible to increase bioavailability and bioactivity of therapeutics and enable selective targeting to damaged joints. Herein, recent studies using nanoparticles for the treatment of RA, namely with liposomes, polymeric nanoparticles, dendrimers, and metallic nanoparticles, have been reviewed. These therapeutic strategies have shown great promise in improving the treatment over that by traditional drugs. The results of these studies confirm that feasibility of the use of nanoparticles is mainly due to their biocompatibility, low toxicity, controlled release, and selective drug delivery to inflamed tissues in animal RA models. Therefore, it is possible to claim that nanotechnology will, in the near future, play a crucial role in advanced treatments and patient-specific therapies for human diseases such as RA.
\end{abstract}

\section{Introduction}

Rheumatoid arthritis (RA) is a chronic inflammatory disease that affects approximately $1 \%$ of the general population worldwide, and is associated with a high degree of morbidity and significant mortality [1,2]. It is characterized by synovial joint inflammation and stiffness, and destruction of cartilages and bones $[3,4]$. The synovial joint structure changes substantially in patients with RA. RA is characterized by an initial

Address correspondence to miguel.oliveira@dep.uminho.pt 
pre-vascular inflammatory phase, followed by a vascular phase with increase in vessel growth. The normal synovial membrane becomes hyperplastic, containing a superficial layer of synovial fibroblast and macrophages, overlying an interstitial zone that comprises of a marked cellular infiltrate, including synovial fibroblasts, macrophages, mast cells, CD4+ T-cells, CD8+ T-cells, natural killer (NK) cells, NKT cells, B-cells, and plasma cells [5]. Inflammation of the synovium invades adjacent cartilage, and subsequently promotes articular destruction. Articular damage is featured by a hypoxic environment and angiogenesis (growth of new blood vessels), characteristics of RA in joints. The increased number of blood vessels is associated with synovial cell hyperplasia and mononuclear cell infiltration. This allows cells to migrate from blood into the inflamed synovium, where proinflammatory cytokines and chemokines play an important role in the pathogenesis of RA [6-8]. Many types of cells have been identified as important participants in the establishment and progression of the disease. T-cells have been implicated as the primary mediators in the pathogenesis of RA, since they contribute to the inflammatory response through elaboration of cytokines and interaction with other cells that perpetuate the inflammation and joint destruction [7]. Pro-inflammatory cytokine tumor necrosis factor- $\alpha$ (TNF- $\alpha$ ) also has an important role in the pathogenesis of RA. It has been shown to be a therapeutic target, since anti-TNF- $\alpha$ agents could induce long-term improvements in the RA symptoms, by protecting the affected joints from tissue degradation [8].

The treatment strategies for RA comprise of the disease-modifying anti-rheumatic drugs (DMARDs), typically supported by non-steroidal anti-inflammatory drugs (NSAIDs) and/or corticosteroids, in order to reduce joint inflammation and pain, maximize joint function, and prevent joint destruction and deformity. Agents that target TNF- $\alpha$ are the leading biological DMARDs. There are three TNF inhibitors well established in the RA market: (i) infliximab, (ii) a chimeric monoclonal antibody, and (iii) the fusion protein etanercept $[9,10]$. Despite recent advances in medical therapeutics, the treatments still raise major efficiency concerns. In fact, patients fail to respond adequately, or become resistant to drug therapy and long-term use of these drugs, probably due to adverse events, such as tuberculosis, fungal infections, lymphomas, liver injury, myelosuppression, and heart failure. Therefore, it is urgent to develop and test new drugs to specifically target inflamed joint, and attenuate damage to healthy tissues. In this regard, nanomedicine is a promising therapeutic approach for RA. Drugloaded nanocarriers, coupled with pathophysiological characteristics of inflamed joints, can amplify the bioavailability and bioactivity of medical therapeutics and possibly promote selective targeting of inflamed joints [11].

Encapsulating bioactive agents into nanocarriers that selectively deliver drugs to the intended sites of action may be achieved through targeted approaches that will be overviewed herein [7].

\section{Nanoparticle systems}

Nanotechnology refers to the ability to measure, design, and manipulate materials at atomic, molecular, and supramolecular level $[12,13]$. The production of nanomaterials for drug delivery can offer new opportunities to provide more focused and precise treatment of the disease at molecular level, and improve the potential therapeutic by reducing its toxicity and enhancing effectiveness. Most drugs are limited by their poor solubility, high toxicity, high dosage, nonspecific delivery, and short circulating half-lives. Nano-size drug delivery focuses on the preparation of bioactive molecules in biocompatible nanosystems, such as nanoparticles (NPs) [14, 15].

NPs have sizes ranging from $1-100 \mathrm{~nm}$. The therapeutic applications of NPs are diverse. One major advantage is the improvement of solubility of poorly water-soluble drugs. NPs of poorly water-soluble drugs can increase the surface area and surface interactions of the NPs, thereby enhancing the dissolution rate and allowing control of the pharmacokinetic properties of the dosage form [16]. NPs also prolong the half-life of systemic circulation of the drug, release drugs at a sustained rate, deliver drugs in a targeted manner to minimize systemic side effects, and deliver two or more drugs simultaneously for combination therapy. Drugs, used in the treatment of RA, are characterized 
by anti-inflammatory and analgesic effect and reduction of inflammatory markers. Drugs such as clodronate, triptolide, methotrexate, indomethacin, dexamethasone (DEX), and small interfering RNA (siRNA) against TNF can be loaded onto NPs by either attaching them to the nanocarrier surface or by encapsulating them within. NPs have been used as drug-delivery systems, with unique architectures, to work as a specific vehicle for a particular disease treatment. These technologies have been studied and used for the treatment of cancer, diabetes, pain, asthma, allergy, and infection $[12-15,17]$. There are different types of nanoparticles including polymeric NPs, liposomes, dendrimers, magnetic NPs, metallic NPs, polymeric micelles, solid lipid nanoparticles, and nanotubes [13, 18, 19] (Fig. 1). The most studied nanoparticles for treating RA are liposomes, polymeric NPs, dendrimers, and metallic nanoparticles.

\subsection{Liposomes}

Liposomes are spherical nanoparticles constituted of bilayer membranes, which are composed of synthetic or natural phospholipids, with an aqueous interior. Physical and chemical properties of a liposome include permeability, charge density, and steric hindrance. They can be used as effective drug delivery systems; drugs may be loaded either in the aqueous compartment or in the lipid membrane. Generally, lipid soluble drugs are incorporated in the liposomal
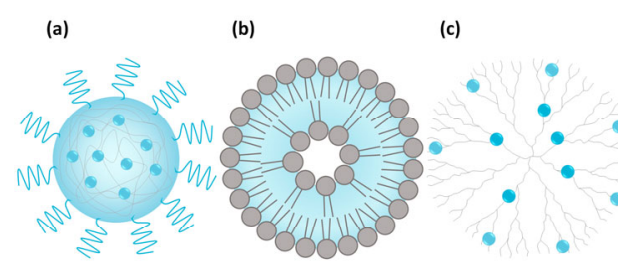

(d)

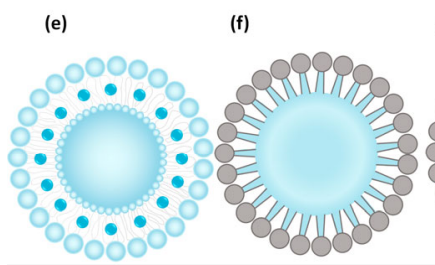

(g)

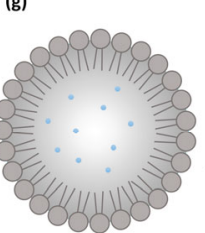

(h)

Figure 1 Schematic of the nanoparticle systems. (a) Polymeric NPs, (b) liposomes, (c) dendrimers, (d) magnetic NPs, (e) metallic NPs, (f) polymeric micelles, (g) solid lipid nanoparticles, and (h) nanotubes. membrane while water soluble drugs are loaded in the compartment [20, 21].

There have been many studies reporting the potential applications of liposomes in RA treatment (Table S1 in the Electronic Supplementary Material (ESM)). Fong et al. [22] studied rabbits (with and without arthritis) injected with either free $[3 \mathrm{H}]$ methotrexate $([3 \mathrm{H}] \mathrm{MTX})$ or liposomes containing [3H]MTX with thioglycollateelicited macrophages in vitro. These authors found that although the catchment of liposomes by the synovium was low, a 40-fold increase in drug retention at the joint was reported, compared to that when free MTX was injected. Liposomes can improve the efficacy and decrease the side effects of drugs in the joint cavity $[23,24]$.

Love and coworkers [25] have studied the effect of liposomes in the inflamed tissues of rats, with and without induced arthritis. Control rats and those with arthritis were injected intravenously, via the tail vein, with four different-sized liposome preparations. This study could verify that there was 10 times more liposome accumulation in the diseased rats than in control rats, and there were differences between small unilamellar vesicle and multilamellar vesicle accumulation in inflamed and control paws; small unilamellar vesicles were accumulated more in the inflamed paws. Another study investigated whether local removal of phagocytic synovial lining cells (SLCs) from the knee by clodronate-liposomes before the introduction of collagen-induced arthritis (CIA) had an effect on the development of cartilage destruction. The study showed that phagocytic SLCs depleted by a single injection of clodronate-liposomes in the knee joint, accompanied by SLCs treated with DEX, decreased cartilage damage [24, 26-28].

Williams et al. [29] studied the effect of liposomeencapsulated methotrexate in the inflamed knee joint to determine if this conjugation would be able to modulate the severity of induced arthritis in rats. The conjugation has been shown to inhibit the release of two pro-inflammatory mediators, TNF- and prostaglandin (PGE2)-stimulated rat peritoneal macrophages in vitro. After the onset of joint inflammation, the rats were treated intravenously with liposomemethotrexate. Liposome encapsulating methotrexate showed significant improvement in the established 
joint inflammation and less toxicity than comparable doses of the free drug.

A study by Watson-Clark et al. [30] examined the use of liposomes as a boron delivery method in rats with CIA. The concentration of boron, delivered by liposomes, was determined after intravenous injection of liposomes. The bio-distribution of liposomes incorporated in the vesicle membrane demonstrated higher synovium/blood boron ratios, reduced boron uptake in synovial tissue, and more rapid blood clearance [28]. Another study analyzed the effect of liposomal benzoporphyrin derivative-monoacid ring A (BPDMA or BPD verteporfin) on the inflamed synovium and articular and peri-articular tissues following its intravenous and intra-articular administration in rabbit model. The study showed that there was a preferential distribution of BDP-MA in the inflamed synovium and its clearance from the synovium was rapid [24, 28, 31] (Fig. 2).

Highton et al. [32] investigated the involvement of clodronate-containing liposomes in anti-macrophage treatment for RA. They used the antigen-induced arthritis model (AIA) in sheep to evaluate the effect of clodronate liposomes. There was an uptake of liposomes into the macrophages in the inflamed joint. They administered an intra-articular injection of clodronate liposome in a group of sheep (group 1), or saline liposome (group 2), and another without arthritis or treatment (group 3). There was no difference in joint diameter or swelling between groups 1 and 2. In these groups histologic scoring were similar, and both were worse than group 3. Despite the possible pro-inflammatory effect, the study was not able to

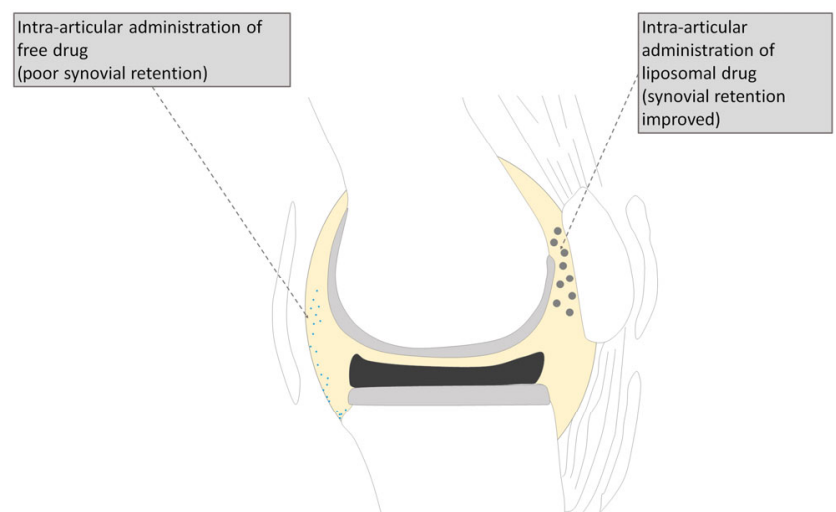

Figure 2 Scheme for the use of liposomes in rheumatoid arthritis (reproduced with permission from Ref. [24], (C) The Authors 2014). prove the therapeutic effect of a single dose of clodronate liposomes in this kind of animal model [28]. Another investigation explored the subcutaneous administration of superoxide dismutase (SOD) entrapped in long circulating liposomes in rats with RA. Results showed that small-sized SOD-liposomes had a higher uptake in the inflamed foot than the large-sized ones. When the localization in the inflamed foot was compared to that in the non-inflamed foot, uptake was higher for the small-sized SOD-liposomes than the large-sized SOD-liposomes. Thus, small-sized liposomes were found to be more effective than the large-sized ones for targeting SOD to arthritic sites by subcutaneous administration [28, 33].

A study made by Srinath et al. [34] investigated the encapsulation of indomethacin in liposomes to determine its anti-inflammatory potential. The study investigated its bio-distribution using conventional liposomes and long-circulating liposomes in a rat RA model. Long-circulating liposomes showed higher targeting efficiency in arthritic paw tissue than conventional liposomes [23, 28].

Ceponis and coworkers [35] showed that intraarticular injection of low doses of liposomal clodronate, in rabbits with established AIA, had anti-inflammatory and anti-erosive effects. There were low levels of TNF, lining cell hyperplasia, and macrophages in the synovium of the liposomal clodronate treated group. Nevertheless, the effect was temporary, and it did not prevent the occurrence of joint erosion over a long term [28].

A study reported by Trif et al. [36] investigated the use of liposome-entrapped lactoferrin (hLf) as a delivery system to prolong hLf retention at local inflammation sites, such as the rheumatoid joint. Investigators compared negatively charged liposomes, positively charged formulations, and free proteins. In vivo studies in rats with CIA showed that the positive liposomes were more effective in prolonging the residence time of hLf in the inflamed joint compared to other liposomes. In 2007, the same research group compared the capacity of free lactoferrin and encapsulated lactoferrin (in liposomes) to prevent an established joint inflammation and to modulate the cytokine response of lymph node (LN) T lymphocytes in $\mathrm{DBA} / 1$ mice with CIA. The anti-inflammatory 
effect was higher in positive liposomes and inferior in the free protein. After a single injection of liposomal hLf, the arthritic score was significantly reduced. Cytokine levels produced by LN $\mathrm{T}$ cells showed a decrease of the pro-inflammatory cytokine (TNF), followed by an increase of the anti-inflammatory cytokine (IL-10), in encapsulated hLf than in free hLf [37].

Another report had compared a dexamethasoneanti-E-selectin immunoconjugate with anti-E-selectin immunoliposomes containing DEX, analyzing the increase in activated endothelial cells in vivo and binding and internalization in vitro. The study showed that dexamethasone-anti-E-selectin was internalized to a larger extent than the anti-E-selectin immunoliposomes, while the high drug-loading capacity of the liposomes may allow a larger quantity of DEX for intracellular delivery. Both accumulated in the activated endothelial cells of inflamed murine skin $[38,39]$.

Metselaar et al. [40] studied the intravenous treatment mechanism of prednisolone phosphate (PLP), encapsulated in long-circulating polyethylene glycol liposomes, to target inflamed joints in rats with AIA. Liposomal PLP proved to be highly effective, with complete reduction of the inflammatory response unlike the same dose of non-encapsulated PLP $[27,28]$. In 2004, the same researchers investigated the mechanism of action of long PEG-liposomeencapsulated PLP in targeting synovial lining cells of inflamed joint and of cartilage destruction in mice with CIA. Mice were treated with conjugated and free PLP few days after establishment of the disease, and liposomal PLP resulted in a strong and lasting resolution of joint inflammation compared to free PLP $[7,41]$. A study made by Harigai et al. [42] evaluated the potential of prednisolone phosphate (PSLP)-containing 3,5-dipentadecyloxybenzamidine hydrochloride (TRX-20) liposomes to treat RA. The conjugated system was added to HFLS cells. The effect of encapsulated PSLP (in TRX-20 liposomes) on HFLS cells was evaluated by the inhibition of inflammatory cytokine and inflammatory chemokine production. The symbiosis of the PSLP-containing liposomes with HFLS cells was 40 times higher than that of PSLP-containing liposomes without TRX-20 [24].
Another study investigated if arginylglycylaspartic acid (RGD) peptide-expose long circulating polyethylene glycol (PEG) liposomes (RGD-PEG-L). The aim of this work was to see if $\alpha v \beta 3$ integrins, expressed on angiogenic vascular endothelial cells (VECs), are efficient to connect VECs at sites of inflammation, and if liposomes containing dexamethasone phosphate (DEXP) could be used as carriers to interfere with the development of experimental arthritis. In rats with AIA, DEXP-encapsulating RGD-PEG-L was evaluated relative to non-targeting liposomes. One intravenous injection of DEXP (encapsulated in RGD-PEG-L) resulted in a strong and lasting anti-arthritic effect in rats with AIA [24, 27, 39, 43]. The folate-linked lipidbased nanoparticle delivery of an NFkB decoy into murine macrophage RAW264.7 cells was also studied. The manifestation of folate receptor in RAW264.7 cells activated lipopolysaccharides, as confirmed by the suppression of FR mRNA. After being transferred via $\mathrm{NP}-\mathrm{F}, \mathrm{NF} \kappa \mathrm{B}$ was detected in the cytoplasm and an inhibitory effect on the translocation of NFkB to the nucleus was observed, presuming that NP-F delivered the NFkB into the cytoplasm. This approach is important for using active macrophages in gene therapy of RA [44].

Rauchhaus et al. [45] analyzed the effect of glucocorticoid dexamethasone phosphate (DXM-P) encapsulated in non PEGylated liposomes in rats with AIA and those without a drug. Injection of liposomal DXM at 6, 24, and $48 \mathrm{~h}$, after arthritis induction, was responsible for removing joint swelling. Liposomal DXM suppressed both chronic inflammation and joint destruction, while free DXM-P failed to prevent joint destruction. Richard et al. [46] investigated the efficacy of a single dose of liposomal clodronate within small unilamellar vesicles (SUVs) to suppress joint inflammation and histological progression of AIA in rats. Rats received a single injection of liposomal clodronate seven days post-arthritis induction. The results showed that liposomal clodronate eliminates synovial macrophages, reduces inflammation, and ameliorates joint destruction in AIA.

In 2001, Richard et al. [47] investigated the role of macrophages, using liposomal clodronate, in the pathogenesis of induced chronic arthritis. Ten days after arthritis induction, rats received a single intravenous 
injection of liposomal clodronate in SUVs. Twenty-six days after treatment, SUVs suppressed the development of arthritis. Macrophage elimination by SUVs was found to inhibit local production of IL- $1 \beta$, IL- 6 , TNF- $\alpha$, and MMP-9, and hence pathogenesis of inflammatory arthritis [28].

A study made by Simões et al. [48] investigated a novel treatment possibility using the SOD liposome mixed lipid vesicles, transfersomes (TFs), in a rat model of AIA. Treatment of animals started at day 1 by the epicutaneous application of SOD-TFs. After this application, the induced rat paw edema was suppressed. It was shown for the first time that SOD incorporated into TFs, and applied onto a skin area not necessarily close to the inflamed tissue, is able to promote non-invasive treatment of induced arthritis [24]. Gaspar et al. [49] studied the biological behavior of acylated superoxide dismutase (Ac-SOD) enzymosomes (enzymes inserted in the lipid bilayer of the liposomes), as compared to SOD located in the aqueous compartment of liposomes. For this study, unmodified liposomes and long circulating liposomes coated with PEG were used. The results showed that liposomes coated with PEG were not influenced by the insertion of Ac-SOD in the lipid bilayers. The therapeutic potential of SOD liposome was compared to that of Ac-SOD enzymosomes in rats with arthritis. Ac-SOD enzymosomes presented a faster antiinflammatory effect, as observed by volume of the inflamed paws. The results allowed the conclusion that Ac-SOD enzymosomes are able to exert therapeutic effect before liposomal disruption and can perform sustained release of the enzymes. Another study determined the therapeutic effect of TNF siRNA administration using liposomes, in rats with RA. The therapeutic effect in rats was assessed after intravenous delivery of TNF siRNA by cationic liposomes. Rats showed improvements when TNF siRNA was administrated, along with the liposome and carrier DNA. There was inhibition of systemic TNF secretion and decrease in the levels of interleukin-6. The study demonstrated the efficiency of liposome carrier system to silence TNF- $\alpha$ in rats with RA $[28,50]$.

\subsection{Polymeric nanoparticles}

Polymeric NPs are biodegradable, biocompatible, and efficient drug-delivery systems. These nanoparticles exhibit great potential for surface modification and functionalization with different ligands, are excellent pharmacokinetic controls, and are able to encapsulate and deliver a variety of therapeutic agents [15]. There are several studies of polymeric nanoparticles for the treatment of RA (Table S2 in the ESM). Gerlag et al. [51] injected mice with CIA with RGD-containing cyclic peptide (RGD-4C) that binds selectively to the $\alpha v \beta 3$ and $\alpha v \beta 5$ integrins in the cells of the inflamed synovium, but not in the cells of normal synovium. $\alpha v \beta 3$ and $\alpha \mathrm{v} \beta 5$ are important in angiogenesis; $\alpha \mathrm{v} \beta 3$ manifests on synovial blood vessels in RA and $\alpha \mathrm{v}$ antagonists injected directly into the joint quell synovitis. The results showed that RGD-4C decreased rheumatoid arthritis symptoms and increased apoptosis of synovial blood vessels.

A study by Kim et al. [52] investigated the effect of single administration of poly(D,L-lactic/glycolic acid) (PLGA) entrapping type II collagen on the development of CIA. This conjugate was studied due to the capacity of each of its elements to be a strong candidate for suppression of autoimmune disease. After a single administration of PLGA-CII in mice, the incidence and severity of arthritis and CIA were significantly reduced. Furthermore, the mice showed a higher level of transforming growth factor $\beta$ (TGF $\beta$ ) mRNA and lower level of TNF- $\alpha$ mRNA expression compared to the other groups of mice. Another study evaluated the fluoresceinamine-bound PLGA (FA-PLGA) copolymer for its application as an intra-articular delivery system in the rat synovium after administering directly into the joint cavity. FA-PLGA nanospheres could be more befitting for delivery to inflamed synovial tissue due to their ability to pass through the synovium and provide local therapeutic action in joint diseases $[53,54]$.

Fienh et al. [55] evaluated the anti-arthritic effect of albumin-coupled methotrexate (MTX-HSA) on potential target cells for albumin-mediated drug delivery. The mouse model of CIA was used to analyze the anti-arthritic effects of MTX and MTX-HSA. Intravenous administration of the injection showed that MTX-HSA is superior to MTX in inhibiting the development of CIA and reducing joint destruction as well as the number of affected paws. MTX-HSA can 
be one of the potential target cells for anti-arthritic treatment $[23,56]$.

A study by Higaki et al. [57] investigated betamethasone sodium phosphate (BSP), encapsulated in PLGA nanoparticles, to target inflamed joints in rats with AIA and in mice with anti-type II collagen antibody induced arthritis (AbIA). The rats were treated intravenously with PLGA-nanosteroid after the initial signs of arthritis; there was a decrease in paw inflammation, and a single injection resulted in a large decrease of the inflammatory response after one week. Furthermore, histological examination showed a significant decrease of the inflammatory cells in the joints $[23,54,58]$. Another study analyzed the anti-inflammatory effect of the triptolide (TP) loaded poly (D,L-lactic acid) (PLA) nanoparticles (TP-PLA-NPs) in rats with AIA. The results showed that TP-PLA-NPs significantly inhibited the adjuvant arthritis and had a significant anti-inflammatory effect after a long-time administration [58, 59].

Mansouri et al. [60] studied the synthesis and characterization of FA-chitosan-DNA nanoparticles and evaluated the cytotoxicity in vitro. Chitosan-DNA and FA-chitosan-DNA nanoparticles were made using reductive amidation and a complex coacervation process. The transfection efficiency depended on various factors such as chemical structure of polycations, cell type, nanoparticle size, composition, and interaction with cells. The results showed that FA-nanoparticles had decreased cytotoxicity (damaging property of a substance comparatively to cells), accompanied by a good DNA condensation and improved cellular uptake (around $118 \mathrm{~nm}$ ) due to the particle size [39].

A study by Wang et al. [61] investigated DEX-HPMA copolymer conjugate to target inflamed joints in rats with RA. The investigators administered DEX-HPMA in a rat model of AIA and found that DEX-HPMA had more anti-inflammatory effect compared to free DEX. Moreover, bone and cartilage preservation with the DEX-HPMA treatment was higher than that with free DEX treatment $[23,39]$. Another study investigated nanoparticles coated with collagen II-binding-peptide (WYRGRL) to target the articular cartilage in RA. Peptide-functionalized nanoparticle-targeted articular cartilage was reported to be much higher than with nanoparticles presenting a scrambled peptide sequence following intra-articular injection in the mouse [62].

Hwang et al. [10] evaluated the use of $\alpha$ methylprednisolone (MP) conjugated cyclodextrin polymer-based nanoparticles (CDP) for rheumatoid arthritis therapy. The conjugate was administered intravenously in rats with CIA. A significant decrease in arthritis score was observed in rats treated with CDP-MP; histological evaluation after 28 days showed decreased synovitis. The study showed that CDP-MP may increase the efficacy for rheumatoid arthritis treatment $[7,11]$.

Another group, Howard et al. [2] investigated chitosan/siRNA nanoparticle-mediated TNF- $\alpha$ reduction in macrophages for anti-inflammatory treatment in mice with CIA. Histological analysis of joints showed little cartilage destruction and inflammatory cell infiltration in anti-TNF- $\alpha$-treated mice. This work showed that chitosan/siRNA nanoparticle-mediated TNF- $\alpha$ knockdown reduces local and systemic inflammation.

Ishihara et al. [4] studied the therapeutic activity of betamethasone disodium 21-phosphate (BP) encapsulated in nanoparticles of PLGA/PLA homopolymers and PEG-block-PLGA/PLA copolymers in rats with AIA and mice with AbIA to target their inflamed joint. The conjugation was intravenously administered. In rats with AIA, there was a $35 \%$ decrease in paw inflammation with a single injection [7, 11, 39]. In 2010, Ishihara et al. [63] investigated the degradation of poly lactic acid and monomethoxy PEG-polylactide block copolymer along with BP in vitro during incubation. BP was found to accumulate in the inflammatory lesion of adjuvant arthritis rat models and the amount of BP gradually decreased. Results suggested that the increase in BP in the lesion was due to the increase in permeability and retention effect. The internalization in inflammatory macrophages was due to the loss of PEG and the release of BP in cells with PEG hydrolysis. Another study examined PEG-DEX conjugate for the treatment of RA. The conjugate was tested in an AIA model. The study revealed that a single PEG-DEX conjugate could improve the ankle joint inflammation in rats with AIA. Histological and bone mineral density analysis showed superior anti-inflammatory and disease 
modifying effects with PEG-DEX conjugate [64].

A study made by Kim et al. [65] examined the efficiency of RA treatment by the development of nanocomplexes based on hyaluronic acid (HA) and PEG-derivatized TNF-related apoptosis inducing ligand) (TRAIL) (PEG-TRAIL). The nanocomplexes were prepared by mixing the positively charged PEG-TRAIL with negatively charged HA. The in vivo bio-distribution and diffusion kinetics of Cy5.5-labeled PEG-TRAIL in mice were observed after subcutaneous injections. Results showed greater therapeutic effects in clinical scores and histology in the delivery of PEG-TRAIL, with nanocomplex in 1\% HA; furthermore, this approach resulted in substantial reduction of serum inflammatory cytokines and collagen-specific antibodies that are responsible for RA.

A study performed by Schmitt et al. [66] investigated hydrophilic nanogels based on chitosan, with hyaluronate surface, loaded with photosensitizers to target macrophages. This study showed a selective uptake by macrophages and increased retention of drugs in the inflamed tissues. While injection-free photosensitizers resulted in rapid liberation from the joints, nanogel-encapsulated photosensitizers remained in the inflamed joints for a longer period of time. The last treatment of the inflamed joints resulted in reduction of inflammation compared to a standard corticoid treatment [39]. Another study investigated chitosan conjugated with folate. Chitosan-DNA and folate-chitosan-DNA were intravenously injected in normal and arthritic rats. This approach was found to facilitate the transfection of folate-chitosan-DNA nanoparticle and more efficiently decrease inflammation in the arthritis rat model $[39,67]$.

Scheinman et al. [68] investigated the functionalization of RGD-PLGA to deliver a STAT1 siRNA in RA model. RGD-PLGA increased both the uptake by paw tissues and prolonged delivery of nanoparticles in the arthritis mouse model. RA regressed with STAT1 siRNA, and STAT1 mRNA levels were lower in the paws of treated animals. This conjugate was shown to be effective in the treatment of arthritis, through a selective inhibition of macrophage and dendritic cell activation. Another study investigated whether a metalloproteinase (MMP-3)-specific polymeric matrix could be used for early diagnosis of arthritis in mice with CIA using a near-infrared fluorescence (NIRF) imaging system [69]. After intravenous administration of the probe, different stages of disease were observed through fluorescence imaging. A higher NIRF signal was recovered from arthritic joints compared to that from normal joints. Immune histochemical analysis and western blotting confirmed that fluorescence in the in vivo imaging was related to MMP-3 activity in the joint tissues [69].

A study by Park et al. [70] investigated hydrophobically modified glycol chitosan nanoparticles (HGC) labeled with Cy5.5 (a dye) in mice with CIA. Activated macrophages expressing Mac-1 molecules effectively phagocyted HGC-Cy5.5 that formed spherical nanoparticles under physiologic conditions. Previous studies showed that HGC nanoparticles mainly accumulate in tumor tissues via leaky vessels, which implied that the pathophysiologic properties increased permeability and retention effect. Due to the abundance of activated macrophages and angiogenesis, characterized by permeable and disorganized structure within the synovial tissues in RA, the investigators hypothesized that HGC nanoparticles may preferentially accumulate within arthritic joints. Histological evaluation confirmed that the mechanism of selective accumulation of HGC-Cy5.5 within synovial tissues included increased phagocytosis and permeability through leaky vessels. Another group, Boekhorst et al. [71] evaluated the anti-inflammatory effect of PLGA nanoparticles loaded with siRNA against TNF- $\alpha$. Intra-articular treatment in joints with TNF- $\alpha$ siRNAloaded NPs resulted in the disease activity reduction; no significant decrease in joint effusions was observed as compared to that in the treatment with PLGA NPs loaded with non-specific control siRNA. The study suggested that HGC-Cy5.5 can play an important role as an RA therapeutic.

Rollet et al. [72] investigated the effect of folic acidhuman serum albumin nanocapsules (FA-HSA) on targeted drug delivery to chronically activated macrophages. Some studies showed that the beta folate receptor (FR $\beta)$ has a high affinity for FA and is expressed by activated macrophages. Therefore, FA-based nanoparticles can provide the possibility of delivering therapeutic agents to activated macrophages without affecting normal cells and tissues. FR $\beta$ - 
expressing macrophages were reported to show an increased binding for FA-HSA compared to that in the absence of FA [56]. Another study developed PLGA nanoparticles co-encapsulating MTX and iron oxide nanoparticles (SPIONS) for RA therapy and imaging applications. The NPs were functionalized with anti-CD64 antibody to specifically target rheumatoid arthritis-associated macrophages, to decrease damage to the tissues. The effect of each component (MTX, SPIONS, and antibody) was compared. In vitro studies enabled the cytotoxic profiling of NPs. MTX indicated high toxicity while MTX-free NPs were only toxic when administered at the highest concentration based on PLGA's biocompatibility [73].

Kim et al. [74] investigated the self-assembled dextran sulphate nanoparticles for targeting rheumatoid arthritis. In vivo results showed that these nanoparticles selectively accumulated in inflamed synovia of mice with CIA, due to their binding to the macrophage scavenger receptors that were overexpressed in the synovia, thus suggesting the potential of dextran sulphate nanoparticles as drug carriers for arthritis therapy.

A study by Heo et al. [75] investigated hyaluronan nanoparticles (HA-NPs) carrying a $\gamma$-secretase inhibitor (DAPT) for rheumatoid arthritis therapy. Results demonstrated that DAPT-loaded HA-NPs (DNPs) attenuated the severity of RA compared to DAPT alone, as evaluated from tissue damage, clinical score, and neutrophil infiltration. Furthermore, DNPs reduced the production of pro-inflammatory cytokines and collagen-specific auto-antibodies in the serum of mice with CIA. In mice with AbIA, a single injection ended the inflammatory response after one week (Fig. 3).

Lee et al. [76] designed a nanocomplex of polymerized siRNA (poly-siRNA) targeting TNF- $\alpha$ with thiolated gycol chitosan (TGC) polymers for the treatment of RA. Poly-siRNA was prepared by selfpolymerization that resulted in nanocomplex of polymerized siRNA with thiolated glycol chitosan (psi-tGC-NPs). These nanoparticles showed in vitro TNF- $\alpha$ gene silencing efficacy and high accumulation at the arthritic joint sites in mice with CIA (Fig. 4). Another study investigated folic acid-etoricoxibbovine serum albumin nanoparticles (F-ETX-NPs) for rheumatoid arthritis treatment [77]. The etoricoxib

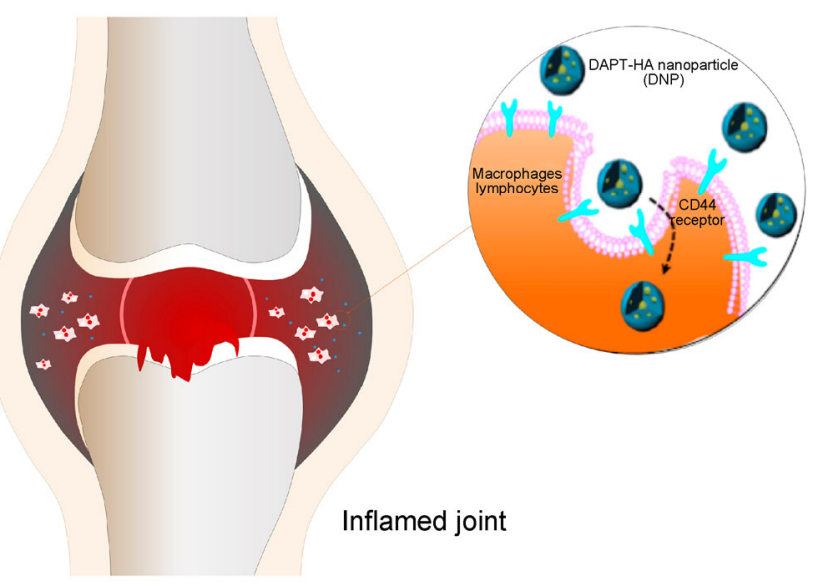

Figure 3 Scheme of DNPs in inflamed joint-targeted drug delivery (reproduced and adapted with permission from Ref. [75], (C) Elsevier 2014).

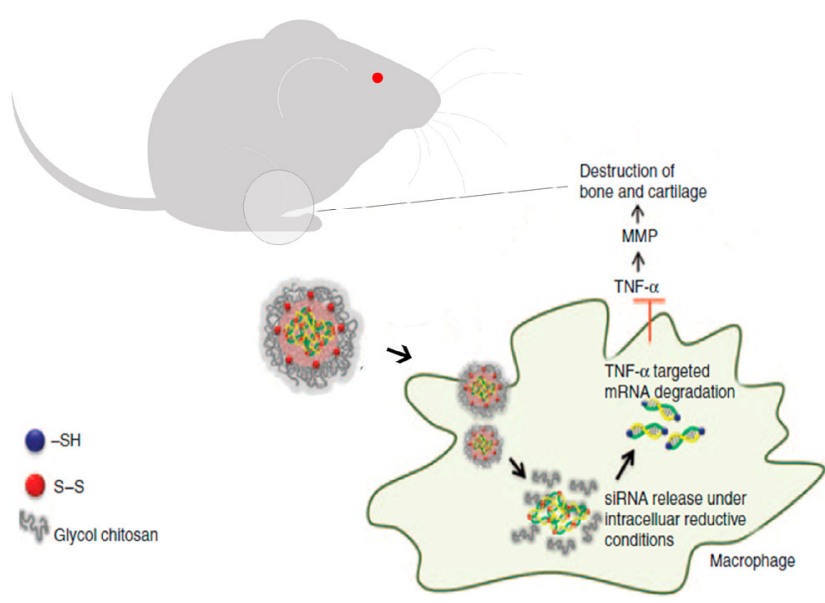

Figure 4 Scheme of psi-tGC-NP delivery into macrophages leading to TNF- $\alpha$ gene knockdown (reproduced and adapted with permission from Ref. [76], (C) The American Society of Gene \& Cell Therapy 2014).

concentration revealed its targeting potential to the activated macrophages. The results suggested that F-ETX-NPs have the potential to target activated macrophages in rheumatoid arthritis, and could be used for early stage diagnosis of rheumatoid arthritis [77].

\subsection{Dendrimers}

Dendrimers are the most interesting class of synthetic, highly branched, and low dispersity macromolecules [78]. A typical dendrimer is composed of different parts (that confer many advantages) such as, a central core and surrounding repeat units that start from the core like branches, and multiple peripheral functional 
groups [79]. The functional groups exhibit a high degree of molecular uniformity and confine molecular weight distribution, in addition to their adjustable size, multivalency, solubility in different media, and biodegradation [80].

Some studies of dendrimers for rheumatoid arthritis treatment are reported in Table S3 in the ESM. The first study used folate-targeted PEG conjugates of G 3.5 PAMAM dendrimer as targeted drug delivery systems for inflammation, and to investigate its distribution standard in arthritic rats. Folate-PEGPAMAM was loaded with indomethacin. Folate-PEG conjugation had 10-20 fold increase in drug loading efficiency and was found to release indomethacin to the joints in a controlled manner. The drug targeting efficiency was the highest in folate-PEG conjugate compared to that in dendrimers without PEG [81].

Another study investigated the poly (amidoamine) dendrimer (generation 5) nanoparticle conjugated with folic acid (FA) and MTX (G5-FA-MTX) as a therapeutic for the inflammatory disease of arthritis. In vitro and in vivo studies were performed in a rat model of CIA in order to evaluate the therapeutic potential of G5-FA-MTX. G5-FA-MTX operated as a strong anti-inflammatory agent and reduced arthritis-induced parameters of inflammation such as paw volume, cartilage damage, bone resorption, etc [82] (Fig. 5).

Hayder et al. [83] explored the therapeutic potential of azabisphosphonate (ABP) dendrimer for target monocytes in the treatment of rheumatoid arthritis. In two animal models, IL-1ra(-/-)mice and mice undergoing $\mathrm{K} / \mathrm{BxN}$ serum transfer, intravenous injections of $\mathrm{ABP}$ dendrimer prevented the development of inflammatory arthritis. The study demonstrated that intravenous injection of dendrimer diminished the inflammatory cytokine levels, normal synovial membrane, and default cartilage destruction and bone erosion [84] (Fig. 6).

\subsection{Metallic nanoparticles}

Metallic nanoparticles comprise a class of materials with very useful properties. These nanoparticles can be synthesized and modified with several functional groups that allow them to be conjugated with antibodies, ligands, magnetic separation, target drug delivery, vehicles for gene and drug delivery and diagnostic

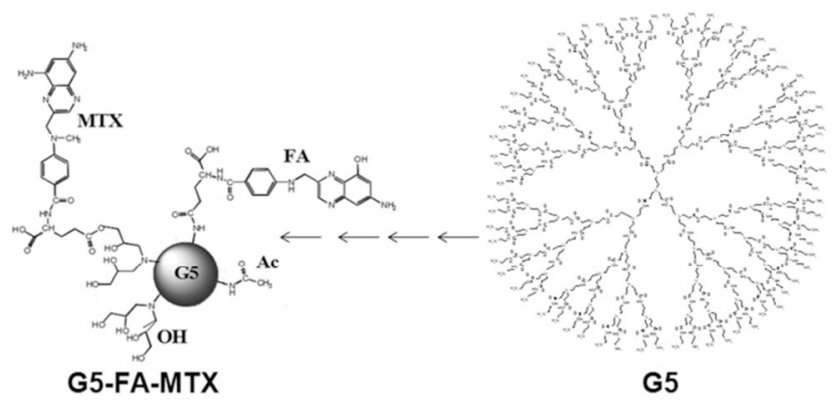

Figure 5 Schematic structure of G5-FA-MTX nanoparticle (reproduced with permission from Ref. [82], (C) American College of Rheumatology 2011).

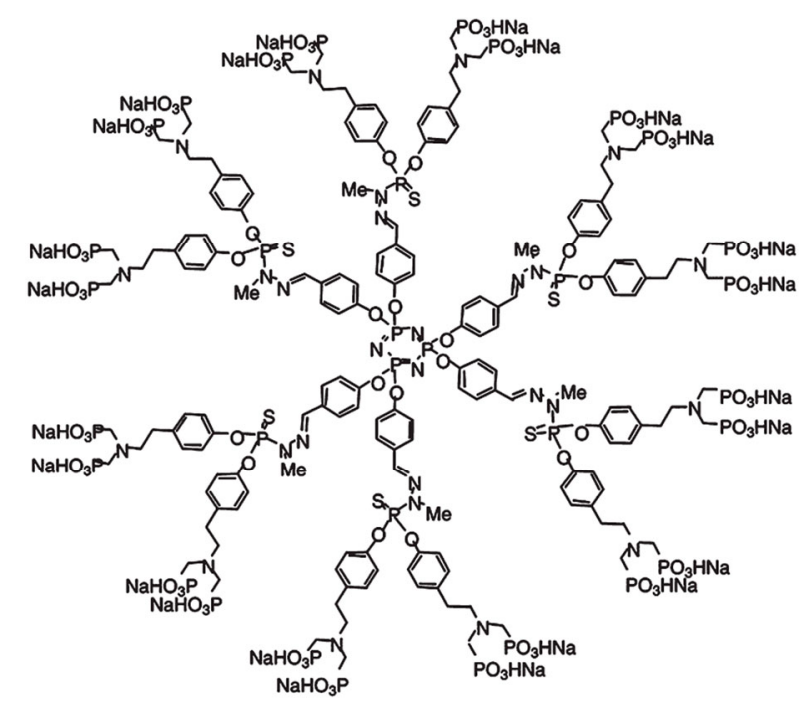

Figure 6 Structure of dendrimer ABP (reproduced with permission from Ref. [83], (C) The American Association for the Advancement of Science 2011).

imaging $[85,86]$.

There have been some studies regarding the use of metallic nanoparticles such as, gold nanoparticles (AuNPs), iron oxide nanoparticles, and silver nanoparticles for the treatment of RA (Table S4 in the ESM). Tsai et al. [87] investigated the effect of intra-articular delivery of nanogold to target vascular endothelial growth factor (VEGF) in rats with CIA. Angiogenesis has an important role in RA and nanogold inhibits the activity of the angiogenic factor, VEGF. The microvessel density, macrophage infiltration extent, and TNF- $\alpha$ and interleukin- $1 \beta$ levels (IL-1 $\beta$ ) in the ankle joint were evaluated. Nanogold was administered intra-articularly to rats with CIA before the onset of arthritis. Nanogold, bound to VEGF in case of RA, resulted in inhibition of synovial fluid, cell proliferation, 
and migration in RA. A diminution in ankle circumference, articular index score, and radiographic scores were observed in the nanogold treated rats with CIA, compared to those in the untreated animals. Histologic analyses of cartilage erosion, leukocyte infiltration, synovial hyperplasia, macrophage infiltration, and TNF- $\alpha$ and IL-1 $\beta$ levels were found to be very low in the ankle joints of treated rats, which resulted in attenuation of arthritis. A study made by Chamberland et al. [88] investigated the potential of photoacoustic tomography in noninvasive monitoring of anti-TNF drug delivery, helped by Etanerceptconjugated AuNPs that were intra-articularly injected in model rats. Results showed that the viability of conjugated TNF antagonist pharmaceutical preparations with AuNPs preserve the mechanism of action of TNF antagonist as evaluated by photoacoustic tomography (PAT) technology with anti-rheumatic drugs. Another study analyzed the effect of HA and AuNPs on animal models of RA. In these animals of RA, local arthritic inflammation was clearly identified upon systematic injection of AuNPs. Results suggest that these nanoparticles can be used as in vivo optical imaging agents for detection of local HA-degrading disease, such as RA [89].

Huang et al. [90] injected Galectin-1-nanogold (AuGAL1) particles intra-articularly into rats with CIA. This conjugation promoted apoptosis of CD4+ T cells, decrease of pro-inflammatory cytokine levels in the ankle joints, and amelioration of clinical symptoms of arthritis.

A study by Lee et al. [91] developed RGD-attached Au half-shell nanoparticles containing MTX to target chemo-photothermal for the treatment of RA. The RGD-attached Au half-shell nanoparticles containing MTX, combined with NIR radiation, showed a higher increase in therapeutic effect, than that with MTX in mice with CIA (Fig. 7). Finally, Lee et al. [92] studied the effect of hyaluronate-gold nanoparticle/Tocilizumab (HA-AuNP/TCZ) complex for the treatment of RA in CIA mouse model. AuNP has anti-angiogenic effect; TCZ is an antibody against the interleukin-6 (IL-6) receptor and utilized as an immunosuppressive drug by interfering with IL- 6 in the pathogenesis of RA. HA has cartilage-protective and lubricant effect. In vitro results showed the binding of $\mathrm{HA}-\mathrm{AuNP} / \mathrm{TCZ}$ to VEGF and IL-6R, and therapeutic potential of HA-AuNP/TCZ (Fig. 8).

Schulze et al. [93] investigated superparamagnetic iron oxide nanoparticles, coated with polyvinyl alcohol (PVA-SPIONS), which was intra-articularly applied in sheep model, and evaluated their uptake by synovial membrane. The uptake was completed in $48 \mathrm{~h}$. The nanoparticles remained within the synovium for at least five days indicating that they could extend the action of intra-articularly applied medication for treating acute or chronic joint diseases. Another study investigated SPIONS, using magnetic resonance imaging (MRI), to track murine mesenchymal stem
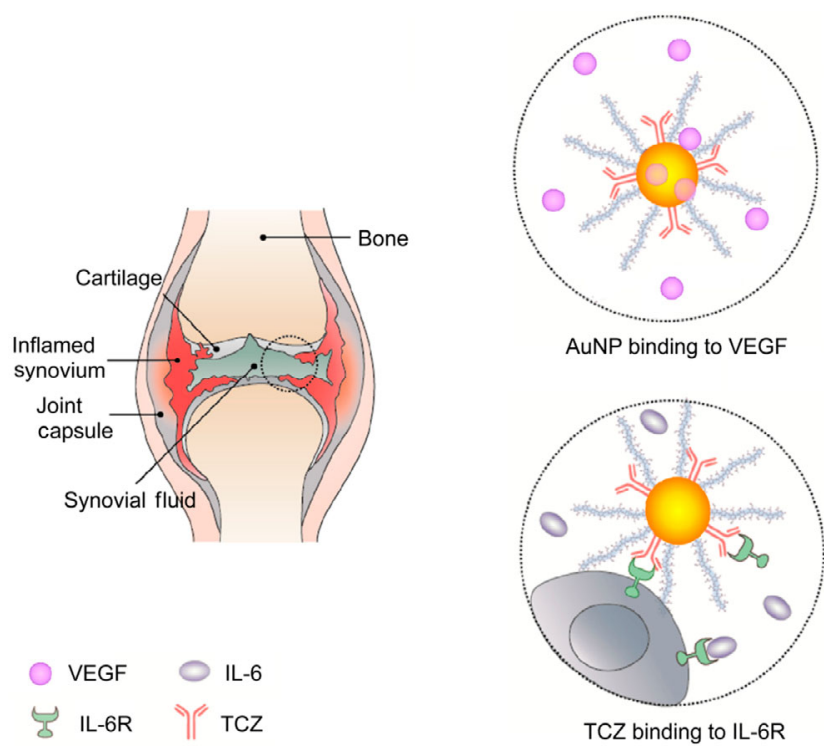

Figure 7 Schematic representation of the production process of RGD-MTX-PLGA AuNPs (reproduced with permission from Ref. [91], (C) American Chemical Society 2013).

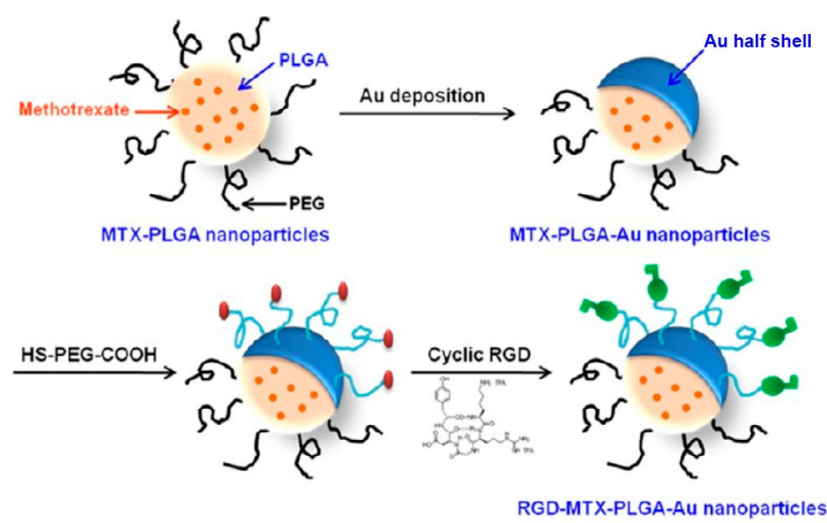

Figure 8 Schematic representation of HA-AuNP/TCZ complex for the treatment of RA (reproduced with permission from Ref. [92], (C) American Chemical Society 2014). 
cells (MSCs) in vivo, labeled as SiMAG, in murine RA model. After RA introduction, the conjugate was implanted via articular injection, and joint swelling monitored as an indication of RA over days. A significant decrease in joint swelling was verified in groups containing SiMAG-labeled and unlabeled mMSCs, in presence of SPIONS does not affect the immunomodulating cells properties. This approach enabled the monitoring of migration of stem cell population within the rheumatic joint in a noninvasive way [3].

Kim et al. [94] investigated multimodal nanoparticles (MNP), containing $\mathrm{Ru}(\mathrm{bpy})_{3} \mathrm{Cl}_{2}$ core surrounded by a paramagnetic coating of gadolinium chelates, as a contrast agent of inflamed synovium in a CIA model. After intravenous administration of MNP, optical and magnetic resonance (MR) images were obtained and clinical disease was identified in MNP-labeled cells (monocytes/macrophages) within the inflamed joints. MR demonstrated a reduction in actively inflamed joints which was evident earlier, than during the course of the disease. MNP proved to be a potential modality contrast agent in inflammatory arthritis and localize to monocytes/macrophages within the inflamed synovium.

Sekar [95] studied the azathioprine-loaded silver nanoparticles for RA treatment, using a green approach. In vitro toxicity of this conjugate was studied by means of a 3T3 NIH fibroblast cell line. This conjugate targets the disease site to release the drug in a controlled way and produce combined effect on the inflammatory sites.

\subsection{Other nanoparticle systems for treatment of RA}

There are various studies regarding the use of NPs for the treatment of RA; this includes solid lipid NPs and polymeric micelles (Table S5 in the ESM).

Ye et al. [96] investigated the intravenous injection formulation of solid lipid nanoparticles (SLNs) loaded with actarit for improved therapeutic efficacy and reduced side-effects associated with its oral formulation in RA pathology. The actarit-loaded SLNs exhibited a longer mean retention time in vivo compared to that in $50 \%$ propylene glycol solution after intravenous injection in rabbits, and the targeting efficiency was enhanced in spleen while the renal distribution of actarit was reduced compared to that after an intravenous injection of actarit solution in mice. Therefore, this approach can promote passive targeting of therapeutic agents for treating RA. Another study explored the anti-inflammatory effect and hepatotoxicity of Tripterygium-loaded solid lipid nanoparticles (TWHF-SLN) in rats with AIA, and the effect of SLN delivery system on decreasing the TWHF-induced hepatotoxicity. After Freund's complete adjuvant agent (FCA) injection, TWHF-SLN group and TWHF group were administered by oral gavage. The paws were evaluated for some days post-injection. Results showed that TWHF-SLN could greatly reduce rat paw volume. Histopathology showed that free TWHF caused more damage to the liver than TWHF-SLN, and the latter increased the anti-inflammatory effects [97].

A study made by Nagai et al. [98] examined the effect of solid nanoparticle of indomethacin (IMC) on the treatment of rheumatoid arthritis in rats with AIA. The rats that received low doses of solid indomethacin nanoparticle after induction of paw edema had similar results as by the administration of a therapeutic dose of conventional IMC. There were less gastrointestinal lesions in the rats upon IMC nanoparticle administration compared to that with conventional IMC. These results showed that IMC nanoparticles may increase the efficiency of rheumatoid arthritis treatment without causing IMC-induced gastrointestinal lesions, because the bioavailability is more than in conventional IMC.

$\alpha v \beta 3$-targeted fumagillin nanoparticles that target angiogenesis to suppress inflammatory arthritis in mice were studied by Zhou et al. [99]. Arthritis was induced using $\mathrm{K} / \mathrm{BxN}$ mouse model of inflammatory arthritis. After arthritis establishment, the mice received some doses of $\alpha \mathrm{v} \beta 3$-targeted fumagillin nanoparticles. The treated mice showed lower disease activity and change in ankle thickness compared to the group that received $\alpha v \beta 3$-targeted fumagillin nanoparticles without drugs. There was a decrease in inflammation and angiogenesis in synovial tissues of animals treated with $\alpha \mathrm{v} \beta 3$-targeted fumagillin nanoparticles.

Koo et al. [100] used sterically stabilized micelles (SSM) as nanocarriers for camptothecin CPT (CPT-SSM). In vitro studies showed that $\mathrm{CPT}$ inhibits synoviocyte proliferation, matrix metalloproteinase expression in chrondrocytes, and angiogenesis. The surface of 
CPT-SSM was modified with vasoactive intestinal peptide (VIP) for active targeting. CPT was, for the first time, reported as effective against CIA, i.e. a single subcutaneous injection of CPT-SSM-VIP, administered to mice with CIA, alleviated joint inflammation for at least one month without systemic toxicity. However, $\mathrm{CPT}$ alone required a much higher dose in order to obtain the same effect.

Table S6 in the ESM shows a summary of the main characteristics of the referred drugs and bioactive agents used for the treatment of rheumatoid arthritis $[101,102]$. These data were mostly obtained from online databases of drugs [101] and proteins [102], in May 2016.

\section{Clinical trials}

Clinical trials are used to evaluate the safety and effectiveness of new treatments. ClinicalTrials.gov. is a website, maintained by the U.S. National Library of Medicine (NLM) at the National Institutes of Health $(\mathrm{NIH})$, which provides access to a database with information on clinical studies, on a wide range of diseases and conditions. Information is provided and updated by the sponsor or principal investigator of the clinical study. A search on this database, using relevant keywords (such as "rheumatoid arthritis", "nanoparticles", "liposomes", "polymeric nanoparticles", or "dendrimers") returned a single registered clinical trial related to the application of nanoparticles in RA management. This trial evaluated the safety of a single intravenous administration of long-circulating liposomal prednisolone disodium phosphate and compared it with pulse intramuscular methylprednisolone in patients with RA. This method is used in the clinics as a bridging therapy to assess the effect of this intervention at the synovial level. Liposomal corticosteroids increase efficacy/safety ratio, compared to corticosteroid administration. Although this study has been completed, no result was published on the database were the study was found [103].

\section{Concluding remarks}

Several treatment alternatives that can be potentially used for the treatment of rheumatoid arthritis, instead of traditional drugs, have been reported. Nanotechnology (making use of nanoparticles) has been developed likewise for the treatment of rheumatoid arthritis. Most of the reported approaches exhibit great specificity in the delivery of the drug loaded-NPs to the site of action. These therapeutic strategies suggest an important potential to improve the efficacy and safety of rheumatoid arthritis therapeutics, with less toxicity and undesired side effects compared to that in traditional drugs (such as, DMARDs, NSAIDs, and corticosteroids). The small size and large surface area of NPs can lead to aggregation, which results in tough physical manipulation, limited drug loading, and burst release. Nevertheless, these limitations could be addressed by, for instance, a careful development of the drug delivery systems, surface modification, drug loading strategies, and release control.

Most of the studied delivery systems in RA therapy involve liposomes. This type of NPs represents the most advanced way of carrier administration, as evidenced in animals and small clinical studies. Nevertheless, more research is needed to get better retention time and control the release rate of the encapsulated drug.

Polymeric NPs also comprise a large part of the total studies conducted till date for the treatment of rheumatoid arthritis. The studies showed a remarkable positive effect, compared to free drugs. However, polymeric NPs are not as extensively studied as the liposomes for the treatment of RA. Therefore, further studies are needed to explore the potential of these nanoparticles. Recent studies, using dendrimers, demonstrated their great potential in the treatment of rheumatoid arthritis. Thus, further studies with such spherical NPs are needed in order to explore their promise further.

Metallic nanoparticles also show great potential, but only few studies have been conducted till date to explore the accurate potential of these nanoparticles.

Other studies reporting the application of nanoparticles for the treatment of rheumatoid arthritis have also shown positive results. Although much research is needed to clarify the underlying mechanisms of these therapeutic approaches, the results of recent studies confirm their promise in this regard due to their physicochemical and biological properties (such 
as biocompatibility, low toxicity, controlled release, and selective drug delivery to inflamed tissues) in animal models with RA.

Despite the encouraging results from most studies, some adjustments in these approaches are still required, especially with respect to efficacy and safety of the developed nanosystems, before being applied in humans. Nonetheless, it can be stated that advanced nanomaterials will certainly play a crucial role in the future, to develop nanopharmaceutics, and in particular, in patient-specific approaches for the treatment of human diseases such as RA.

\section{Acknowledgements}

The authors thank the financial support under the ARTICULATE project (No. QREN-13/SI/2011-23189). This study was also funded by the Portuguese Foundation for Science and Technology (FCT) project OsteoCart (No. PTDC/CTM-BPC/115977/2009), as well as the European Union's FP7 Programme under grant agreement no REGPOT-CT2012-316331-POLARIS. The FCT distinction attributed to J. M. O. under the Investigator FCT program (No. IF/00423/2012) is also greatly acknowledged. C. G. also wished to acknowledge FCT for supporting her research (No. SFRH/BPD/94277/2013).

Electronic Supplementary Material: Supplementary material (Tables S1-S6) is available in the online version of this article at https://doi.org/10.1007/s12274-0182071-3.

\section{References}

[1] Barnes, T.; Moots, R. Targeting nanomedicines in the treatment of rheumatoid arthritis: Focus on certolizumab pegol. Int. J. Nanomedicine 2007, 2, 3-7.

[2] Howard, K. A.; Paludan, S. R.; Behlke, M. A.; Besenbacher, F.; Deleuran, B.; Kjems, J. Chitosan/siRNA nanoparticlemediated TNF- $\alpha$ knockdown in peritoneal macrophages for anti-inflammatory treatment in a murine arthritis model. Mol. Ther. 2009, 17, 162-168.

[3] Markides, H.; Kehoe, O.; Morris, R. H.; El Haj, A. J. Whole body tracking of superparamagnetic iron oxide nanoparticlelabelled cells-A rheumatoid arthritis mouse model. Stem
Cell Res. Ther. 2013, 4, 126.

[4] Ishihara, T.; Kubota, T.; Choi, T.; Higaki, M. Treatment of experimental arthritis with stealth-type polymeric nanoparticles encapsulating betamethasone phosphate. J. Pharmacol. Exp. Ther. 2009, 329, 412-417.

[5] McInnes, I. B.; Schett, G. Cytokines in the pathogenesis of rheumatoid arthritis. Nat. Rev. Immunol. 2007, 7, 429-442.

[6] Marrelli, A.; Cipriani, P.; Liakouli, V.; Carubbi, F.; Perricone, C.; Perricone, R.; Giacomelli, R. Angiogenesis in rheumatoid arthritis: A disease specific process or a common response to chronic inflammation? Autoimmun. Rev. 2011, 10, 595-598.

[7] Pham, C. T. N. Nanotherapeutic approaches for the treatment of rheumatoid arthritis. Wiley Interdiscip. Rev.: Nanomed. Nanobiotechnol. 2011, 3, 607-619.

[8] Oda, K.; Minata, M. Drug free remission after steroiddependent disappearance of lymphoproliferative disorder in rheumatoid arthritis patient treated with TNF-alpha blockade: Case study. SpringerPlus 2015, 4, 41.

[9] Stoll, J. G.; Yasothan, U. Rheumatoid arthritis market. Nat. Rev. Drug Discov. 2009, 8, 693-694.

[10] Hwang, J.; Rodgers, K.; Oliver, J. C.; Schluep, T. $\alpha$-Methylprednisolone conjugated cyclodextrin polymer-based nanoparticles for rheumatoid arthritis therapy. Int. J. Nanomedicine 2008, 3, 359-371.

[11] Rubinstein, I.; Weinberg, G. L. Nanomedicines for chronic non-infectious arthritis: The clinician's perspective. Maturitas 2012, 73, 68-73.

[12] Boulaiz, H.; Alvarez, P. J.; Ramirez, A.; Marchal, J. A.; Prados, J.; Rodríguez-Serrano, F.; Perán, M.; Melguizo, C.; Aranega, A. Nanomedicine: Application areas and development prospects. Int. J. Mol. Sci. 2011, 12, 3303-3321.

[13] Zhang, L.; Gu, F. X.; Chan, J. M.; Wang, A. Z.; Langer, R. S.; Farokhzad, O. C. Nanoparticles in medicine: Therapeutic applications and developments. Clin. Pharmacol. Ther. 2008, 83, 761-769.

[14] Mukherjee, B. Nanosize drug delivery system. Curr. Pharm. Biotechnol. 2013, 14, 1221.

[15] Parveen, S.; Misra, R.; Sahoo, S. K. Nanoparticles: A boon to drug delivery, therapeutics, diagnostics and imaging. Nanomedicine 2012, 8, 147-166.

[16] Merisko-Liversidge, E. M.; Liversidge, G. G. Drug nanoparticles: Formulating poorly water-soluble compounds. Toxicol. Pathol. 2008, 36, 43-48.

[17] Kahlenberg, J. M.; Fox, D. A. Advances in the medical treatment of rheumatoid arthritis. Hand Clin. 2011, 27, 11-20.

[18] Abhilash, M. Potential applications of Nanoparticles. Int. J. Pharm. Bio Sci. 2010, 1, 1-12. 
[19] Mudshinge, S. R.; Deore, A. B.; Patil, S.; Bhalgat, C. M. Nanoparticles: Emerging carriers for drug delivery. Saudi Pharmaceut. J. 2011, 19, 129-141.

[20] Surendiran, A.; Sandhiya, S.; Pradhan, S. C.; Adithan, C. Novel applications of nanotechnology in medicine. Indian $J$. Med. Res. 2009, 130, 689-701.

[21] Malam, Y.; Loizidou, M.; Seifalian, A. M. Liposomes and nanoparticles: Nanosized vehicles for drug delivery in cancer. Trends Pharmacol. Sci. 2009, 30, 592-599.

[22] Foong, W. C.; Green, K. L. Association of liposomeentrapped $[3 \mathrm{H}]$ methotrexate with thioglycollate-elicited macrophages in-vitro. J. Pharm. Pharmacol. 1988, 40, 171-175.

[23] Tarner, I. H.; Müller-Ladner, U. Drug delivery systems for the treatment of rheumatoid arthritis. Exp. Opin. Drug Deliv. 2008, 5, 1027-1037.

[24] Kapoor, B.; Singh, S. K.; Gulati, M.; Gupta, R.; Vaidya, Y. Application of liposomes in treatment of rheumatoid arthritis: Quo vadis. Sci. World J. 2014, 2014, 978351.

[25] Love, W. G.; Amos, N.; Kellaway, I. W.; Williams, B. D. Specific accumulation of technetium- $99 \mathrm{~m}$ radiolabelled, negative liposomes in the inflamed paws of rats with adjuvant induced arthritis: Effect of liposome size. Ann. Rheum. Dis. 1989, 48, 143-148.

[26] van Lent, P. L. E. M.; Holthuysen, A. E. M.; van Rooijen, N.; van De Putte, L. B. A.; van Den Berg, W. B. Local removal of phagocytic synovial lining cells by clodronate-liposomes decreases cartilage destruction during collagen type II arthritis. Ann. Rheum. Dis. 1998, 57, 408-413.

[27] Ulbrich, W.; Lamprecht, A. Targeted drug-delivery approaches by nanoparticulate carriers in the therapy of inflammatory diseases. J. Roy. Soc. Interface 2010, 7(Suppl 1), S55-S66.

[28] van den Hoven, J. M.; van Tomme, S. R.; Metselaar, J. M.; Nuijen, B.; Beijnen, J. H.; Storm, G. Liposomal drug formulations in the treatment of rheumatoid arthritis. Mol. Pharmaceutics 2011, 8, 1002-1015.

[29] Williams, A. S.; Camilleri, J. P.; Williams, B. D. Suppression of adjuvant-induced arthritis by liposomally conjugated methotrexate in the rat. Rheumatology 1994, 33, 530-533.

[30] Watson-Clark, R. A.; Banquerigo, M. L.; Shelly, K.; Hawthorne, M. F.; Brahn, E. Model studies directed toward the application of boron neutron capture therapy to rheumatoid arthritis: Boron delivery by liposomes in rat collagen-induced arthritis. Proc. Natl. Acad. Sci. USA 1998, 95, 2531-2534.

[31] Chowdhary, R. K.; Ratkay, L. G.; Canaan, A. J.; Waterfield, J. D.; Richter, A. M.; Levy, J. G. Uptake of Verteporfin ${ }^{\circledR}$ by articular tissues following systemic and intra-articular administration. Biopharm. Drug Dispos. 1998, 19, 395-400.

[32] Highton, J.; Guévremont, D.; Thomson, J.; Carlisle, B.;
Tucker, I. A trial of clodronate-liposomes as anti-macrophage treatment in a sheep model of arthritis. Clin. Exp. Rheumatol. 1999, 17, 43-48.

[33] Corvo, M. L.; Boerman, O. C.; Oyen, W. J. G.; Jorge, J. C. S.; Cruz, M. E. M.; Crommelin, D. J. A.; Storm, G. Subcutaneous administration of superoxide dismutase entrapped in long circulating liposomes: In vivo fate and therapeutic activity in an inflammation model. Pharm. Res. 2000, 17, 600-606.

[34] Srinath, P.; Chary, M. G.; Vyas, S. P.; Diwan, P. V. Long-circulating liposomes of indomethacin in arthritic rats-A biodisposition study. Pharm. Acta Helv. 2000, 74, 399-404.

[35] Čeponis, A.; Waris, E.; Mönkkönen, J.; Laasonen, L.; Hyttinen, M.; Solovieva, S. A.; Hanemaaijer, R.; Bitsch, A.; Konttinen, Y. T. Effects of low-dose, noncytotoxic, intraarticular liposomal clodronate on development of erosions and proteoglycan loss in established antigen-induced arthritis in rabbits. Arthritis Rheum. 2001, 44, 1908-1916.

[36] Trif, M.; Guillen, C.; Vaughan, D. M.; Telfer, J. M.; Brewer, J. M.; Roseanu, A.; Brock, J. H. Liposomes as possible carriers for lactoferrin in the local treatment of inflammatory diseases. Exp. Biol. Med. 2001, 226, 559-564.

[37] Trif, M.; Roseanu, A.; Brock, J. H.; Brewer, J. M. Designing lipid nanostructures for local delivery of biologically active macromolecules. J. Liposome Res. 2007, 17, 237-248.

[38] Everts, M.; Koning, G. A.; Kok, R. J.; Ásgeirsdóttir, S. A.; Vestweber, D.; Meijer, D. K. F.; Storm, G.; Molema, G. In vitro cellular handling and in vivo targeting of E-selectindirected immunoconjugates and immunoliposomes used for drug delivery to inflamed endothelium. Pharm. Res. 2003, 20, 64-72.

[39] Mitragotri, S.; Yoo, J.-W. Designing micro- and nanoparticles for treating rheumatoid arthritis. Arch. Pharm. Res. 2011, 34, 1887-1897.

[40] Metselaar, J. M.; Wauben, M. H. M.; Wagenaar-Hilbers, J. P. A.; Boerman, O. C.; Storm, G. Complete remission of experimental arthritis by joint targeting of glucocorticoids with long-circulating liposomes. Arth. Rheumatol. 2003, 48, 2059-2066.

[41] Metselaar, J. M.; Van den Berg, W. B.; Holthuysen, A. E. M.; Wauben, M. H. M.; Storm, G.; Van Lent, P. L. E. M. Liposomal targeting of glucocorticoids to synovial lining cells strongly increases therapeutic benefit in collagen type II arthritis. Ann. Rheum. Dis. 2004, 63, 348-353.

[42] Harigai, T.; Hagiwara, H.; Ogawa, Y.; Ishizuka, T.; Kaneda, S.; Kimura, J. Prednisolone phosphate-containing TRX-20 liposomes inhibit cytokine and chemokine production in human fibroblast-like synovial cells: A novel approach to rheumatoid arthritis therapy. J. Pharm. Pharmacol. 2007, 
59, 137-143.

[43] Koning, G. A.; Schiffelers, R. M.; Wauben, M. H. M.; Kok, R. J.; Mastrobattista, E.; Molema, G.; ten Hagen, T. L. M.; Storm, G. Targeting of angiogenic endothelial cells at sites of inflammation by dexamethasone phosphate-containing RGD peptide liposomes inhibits experimental arthritis. Arth Rheumatol. 2006, 54, 1198-1208.

[44] Hattori, Y.; Sakaguchi, M.; Maitani, Y. Folate-linked lipidbased nanoparticles deliver a NFאB decoy into activated murine macrophage-like RAW264.7 cells. Biol. Pharm. Bull. 2006, 29, 1516-1520.

[45] Rauchhaus, U.; Kinne, R. W.; Pohlers, D.; Wiegand, S.; Wölfert, A.; Gajda, M.; Bräuer, R.; Panzner, S. Targeted delivery of liposomal dexamethasone phosphate to the spleen provides a persistent therapeutic effect in rat antigen-induced arthritis. Ann. Rheum. Dis. 2009, 68, 1933-1934.

[46] Richards, P. J.; Williams, A. S.; Goodfellow, R. M.; Williams, B. D. Liposomal clodronate eliminates synovial macrophages, reduces inflammation and ameliorates joint destruction in antigen-induced arthritis. Rheumatology 1999 , 38, 818-825.

[47] Richards, P. J.; Williams, B. D.; Williams, A. S. Suppression of chronic streptococcal cell wall-induced arthritis in Lewis rats by liposomal clodronate. Rheumatology 2001, 40, 978-987.

[48] Simões, S.; Delgado, T. C.; Lopes, R. M.; Jesus, S.; Ferreira, A. A.; Morais, J. A.; Cruz, M. E. M.; Corvo, M. L.; Martins, M. B. F. Developments in the rat adjuvant arthritis model and its use in therapeutic evaluation of novel non-invasive treatment by SOD in Transfersomes. J. Control. Release 2005, 103, 419-434.

[49] Gaspar, M. M.; Boerman, O. C.; Laverman, P.; Corvo, M. L.; Storm, G.; Cruz, M. E. M. Enzymosomes with surface-exposed superoxide dismutase: In vivo behaviour and therapeutic activity in a model of adjuvant arthritis. $J$. Control. Release 2007, 117, 186-195.

[50] Khoury, M.; Louis-Plence, P.; Escriou, V.; Noel, D.; Largeau, C.; Cantos, C.; Scherman, D.; Jorgensen, C.; Apparailly, F. Efficient new cationic liposome formulation for systemic delivery of small interfering RNA silencing tumor necrosis factor $\alpha$ in experimental arthritis. Arth. Rheumatol. 2006, 54, 1867-1877.

[51] Gerlag, D. M.; Borges, E.; Tak, P. P.; Ellerby, H. M.; Bredesen, D. E.; Pasqualini, R.; Ruoslahti, E.; Firestein, G. S. Suppression of murine collagen-induced arthritis by targeted apoptosis of synovial neovasculature. Arth. Res. Ther. 2001, 3,357 .

[52] Kim, W. U.; Lee, W. K.; Ryoo, J. W.; Kim, S. H.; Kim, J.; Youn, J.; Min, S. Y.; Bae, E. Y.; Hwang, S. Y.; Park, S. H. et al. Suppression of collagen-induced arthritis by single administration of poly (lactic-co-glycolic acid) nanoparticles entrapping type II collagen: A novel treatment strategy for induction of oral tolerance. Arth. Rheumatol. 2002, 46, 1109-1120.

[53] Horisawa, E.; Kubota, K.; Tuboi, I.; Sato, K.; Yamamoto, H.; Takeuchi, H.; Kawashima, Y. Size-dependency of DL-lactide/ glycolide copolymer particulates for intra-articular delivery system on phagocytosis in rat synovium. Pharm. Res. 2002, 19, 132-139.

[54] Butoescu, N.; Jordan, O.; Doelker, E. Intra-articular drug delivery systems for the treatment of rheumatic diseases: A review of the factors influencing their performance. Eur. $J$. Pharm. Biopharm. 2009, 73, 205-218.

[55] Fiehn, C.; Müller-Ladner, U.; Gay, S.; Krienke, S.; Freudenberg-Konrad, S.; Funk, J.; Ho, A. D.; Sinn, H.; Wunder, A. Albumin-coupled methotrexate (MTX-HSA) is a new anti-arthritic drug which acts synergistically to MTX. Rheumatology 2004, 43, 1097-1105.

[56] Ren, K.; Dusad, A.; Dong, R.; Quan, L. D. Albumin as a delivery carrier for rheumatoid arthritis. J. Nanomed. Nanotechol. 2013, 4, 176.

[57] Higaki, M.; Ishihara, T.; Izumo, N.; Takatsu, M.; Mizushima, Y. Treatment of experimental arthritis with poly (D, L-lactic/ glycolic acid) nanoparticles encapsulating betamethasone sodium phosphate. Ann. Rheum. Dis. 2005, 64, 1132-1136.

[58] Patel, J.; Jigar, B.; Shah, H.; Patel, D. Novel drug delivery technologies for the treatment of rheumatoid arthritis. Internet J. Med. Technol. 2008, 5, 1-11.

[59] Liu, M. X.; Dong, J.; Yang, Y. J.; Yang, X. L.; Xu, H. B. Anti-inflammatory effects of triptolide loaded poly (D, L-lactic acid) nanoparticles on adjuvant-induced arthritis in rats. J. Ethnopharmacol. 2005, 97, 219-225.

[60] Mansouri, S.; Cuie, Y.; Winnik, F.; Shi, Q.; Lavigne, P.; Benderdour, M.; Beaumont, E.; Fernandes, J. C. Characterization of folate-chitosan-DNA nanoparticles for gene therapy. Biomaterials 2006, 27, 2060-2065.

[61] Wang, D.; Miller, S. C.; Liu, X.-M.; Anderson, B.; Wang, X. S.; Goldring, S. R. Novel dexamethasone-HPMA copolymer conjugate and its potential application in treatment of rheumatoid arthritis. Arth. Res. Ther. 2007, 9, R2.

[62] Rothenfluh, D. A.; Bermudez, H.; O’Neil, C. P.; Hubbell, J. A. Biofunctional polymer nanoparticles for intra-articular targeting and retention in cartilage. Nat. Mater. 2008, 7, 248-254.

[63] Ishihara, T.; Takahashi, M.; Higaki, M.; Mizushima, Y.; Mizushima, T. Preparation and characterization of a nanoparticulate formulation composed of PEG-PLA and PLA as anti-inflammatory agents. Int. J. Pharm. 2010, 385, 170-175. 
[64] Liu, X.-M.; Quan, L.-D.; Tian, J.; Laquer, F. C.; Ciborowski, P.; Wang, D. Syntheses of click PEG-dexamethasone conjugates for the treatment of rheumatoid arthritis. Biomacromolecules 2010, 11, 2621-2628.

[65] Kim, Y.-J.; Chae, S. Y.; Jin, C.-H.; Sivasubramanian, M.; Son, S.; Choi, K. Y.; Jo, D.-G.; Kim, K.; Kwon, I. C.; Lee, K. C. et al. Ionic complex systems based on hyaluronic acid and PEGylated TNF-related apoptosis-inducing ligand for treatment of rheumatoid arthritis. Biomaterials 2010, 31, 9057-9064.

[66] Schmitt, F.; Lagopoulos, L.; Käuper, P.; Rossi, N.; Busso, N.; Barge, J.; Wagnières, G.; Laue, C.; Wandrey, C.; Juillerat-Jeanneret, L. Chitosan-based nanogels for selective delivery of photosensitizers to macrophages and improved retention in and therapy of articular joints. J. Control. Release 2010, 144, 242-250.

[67] Shi, Q.; Wang, H. J.; Tran, C.; Qiu, X. P.; Winnik, F. M.; Zhang, X. L.; Dai, K. R.; Benderdour, M.; Fernandes, J. C. Hydrodynamic delivery of chitosan-folate-DNA nanoparticles in rats with adjuvant-induced arthritis. J. Biomed. Biotechnol. 2011, 2011, Article ID 148763.

[68] Scheinman, R. I.; Trivedi, R.; Vermillion, S.; Kompella, U. B. Functionalized STAT1 siRNA nanoparticles regress rheumatoid arthritis in a mouse model. Nanomedicine 2011, 6, 1669-1682.

[69] Ryu, J. H.; Lee, A.; Chu, J. U.; Koo, H.; Ko, C. Y.; Kim, H. S.; Yoon, S. Y.; Kim, B. S.; Choi, K.; Kwon, I. C. et al. Early diagnosis of arthritis in mice with collagen-induced arthritis, using a fluorogenic matrix metalloproteinase 3-specific polymeric probe. Arth. Rheumatol. 2011, 63, 3824-3832.

[70] Park, K. S.; Kang, J. H.; Sa, K. H.; Koo, H. B.; Cho, H. J.; Nam, E. J.; Youn, I. C.; Kim, K. M.; Kim, I. S.; Kwon, I. C. et al. In vivo quantitative measurement of arthritis activity based on hydrophobically modified glycol chitosan in inflammatory arthritis: More active than passive accumulation. Mol. Imaging 2012, 11, 389-400.

[71] Te Boekhorst, B. C. M.; Jensen, L. B.; Colombo, S.; Varkouhi, A. K.; Schiffelers, R. M.; Lammers, T.; Storm, G.; Nielsen, H. M.; Strijkers, G. J.; Foged, C. et al. MRI-assessed therapeutic effects of locally administered PLGA nanoparticles loaded with anti-inflammatory siRNA in a murine arthritis model. J. Control. Release 2012, 161, 772-780.

[72] Rollett, A.; Reiter, T.; Nogueira, P.; Cardinale, M.; Loureiro, A.; Gomes, A.; Cavaco-Paulo, A.; Moreira, A.; Carmo, A. M.; Guebitz, G. M. Folic acid-functionalized human serum albumin nanocapsules for targeted drug delivery to chronically activated macrophages. Int. J. Pharm. 2012, 427, 460-466.
[73] Albuquerque, J.; Moura, C. C.; Sarmento, B.; Reis, S. Solid lipid nanoparticles: A potential multifunctional approach towards rheumatoid arthritis theranostics. Molecules 2015, 20, 11103-11118.

[74] Kim, S.-H.; Kim, J.-H.; You, D. G.; Saravanakumar, G.; Yoon, H. Y.; Choi, K. Y.; Thambi, T.; Deepagan, V. G.; Jo, D.-G.; Park, J. H. Self-assembled dextran sulphate nanoparticles for targeting rheumatoid arthritis. Chem. Commun. 2013, 49, 10349-10351.

[75] Heo, R.; Park, J.-S.; Jang, H. J.; Kim, S.-H.; Shin, J. M.; Suh, Y. D.; Jeong, J. H.; Jo, D.-G.; Park, J. H. Hyaluronan nanoparticles bearing $\gamma$-secretase inhibitor: In vivo therapeutic effects on rheumatoid arthritis. J. Control. Release 2014, 192, 295-300.

[76] Lee, S. J.; Lee, A.; Hwang, S. R.; Park, J.-S.; Jang, J.; Huh, M. S.; Jo, D.-G.; Yoon, S.-Y.; Byun, Y.; Kim, S. H. et al. TNF- $\alpha$ gene silencing using polymerized siRNA/thiolated glycol chitosan nanoparticles for rheumatoid arthritis. Mol. Ther. 2014, 22, 397-408.

[77] Bilthariya, U.; Jain, N.; Rajoriya, V.; Jain, A. K. Folateconjugated albumin nanoparticles for rheumatoid arthritistargeted delivery of etoricoxib. Drug Dev. Ind. Pharm. 2015, 41, 95-104.

[78] Oliveira, J. M.; Kotobuki, N.; Marques, A. P.; Pirraco, R. P.; Benesch, J.; Hirose, M.; Costa, S. A.; Mano, J. F.; Ohgushi, H.; Reis, R. L. Surface engineered carboxymethylchitosan/ poly(amidoamine) dendrimer nanoparticles for intracellular targeting. Adv. Funct. Mater. 2008, 18, 1840-1853.

[79] Yu, M. M.; Jie, X.; Xu, L.; Chen, C.; Shen, W. L.; Cao, Y. N.; Lian, G.; Qi, R. Recent advances in dendrimer research for cardiovascular diseases. Biomacromolecules 2015, 16, 2588-2598.

[80] Wu, L.-P.; Ficker, M.; Christensen, J. B.; Trohopoulos, P. N.; Moghimi, S. M. Dendrimers in medicine: Therapeutic concepts and pharmaceutical challenges. Bioconjugate Chem. 2015, 26, 1198-1211.

[81] Chandrasekar, D.; Sistla, R.; Ahmad, F. J.; Khar, R. K.; Diwan, P. V. Folate coupled poly(ethyleneglycol) conjugates of anionic poly(amidoamine) dendrimer for inflammatory tissue specific drug delivery. J. Biomed. Mater. Res. A 2007, 82, 92-103.

[82] Thomas, T. P.; Goonewardena, S. N.; Majoros, I. J.; Kotlyar, A.; Cao, Z. Y.; Leroueil, P. R.; Baker, J. R. Folate-targeted nanoparticles show efficacy in the treatment of inflammatory arthritis. Arth. Rheumatol. 2011, 63, 2671-2680.

[83] Hayder, M.; Poupot, M.; Baron, M.; Nigon, D.; Turrin, C.-O.; Caminade, A.-M.; Majoral, J.-P.; Eisenberg, R. A.; Fournié, J.-J.; Cantagrel, A. et al. A phosphorus-based dendrimer targets inflammation and osteoclastogenesis in 
experimental arthritis. Sci. Trans. Med. 2011, 3, 81ra35.

[84] Bosch, X. Dendrimers to treat rheumatoid arthritis. ACS Nano 2011, 5, 6779-6785.

[85] Edmundson, M. C.; Capeness, M.; Horsfall, L. Exploring the potential of metallic nanoparticles within synthetic biology. New Biotechnol. 2014, 31, 572-578.

[86] Mody, V. V.; Siwale, R.; Singh, A.; Mody, H. R. Introduction to metallic nanoparticles. J. Pharm. Bioallied Sci. 2010, 2, 282-289.

[87] Tsai, C. Y.; Shiau, A. L.; Chen, S. Y.; Chen, Y. H.; Cheng, P. C.; Chang, M. Y.; Chen, D. H.; Chou, C. H.; Wang, C. R.; Wu, C. L. Amelioration of collagen-induced arthritis in rats by nanogold. Arth. Rheumatol. 2007, 56, 544-554.

[88] Chamberland, D. L.; Agarwal, A.; Kotov, N.; Fowlkes, J. B.; Carson, P. L.; Wang, X. D. Photoacoustic tomography of joints aided by an Etanercept-conjugated gold nanoparticle contrast agent-An ex vivo preliminary rat study. Nanotechnology 2008, 19, 095101.

[89] Lee, H.; Lee, K.; Kim, I. K.; Park, T. G. Synthesis, characterization, and in vivo diagnostic applications of hyaluronic acid immobilized gold nanoprobes. Biomaterials 2008, 29, 4709-4718.

[90] Huang, Y.-J.; Shiau, A.-L.; Chen, S.-Y.; Chen, Y.-L.; Wang, C.-R.; Tsai, C.-Y.; Chang, M.-Y.; Li, Y.-T.; Leu, C.-H.; Wu, C.-L. Multivalent structure of galectin-1-nanogold complex serves as potential therapeutics for rheumatoid arthritis by enhancing receptor clustering. Eur. Cell. Mater. 2012, 23, 170-181.

[91] Lee, S.-M.; Kim, H. J.; Ha, Y.-J.; Park, Y. N.; Lee, S.-K.; Park, Y.-B.; Yoo, K.-H. Targeted chemo-photothermal treatments of rheumatoid arthritis using gold half-shell multifunctional nanoparticles. ACS Nano 2013, 7, 50-57.

[92] Lee, H.; Lee, M.-Y.; Bhang, S. H.; Kim, B.-S.; Kim, Y. S.; Ju, J. H.; Kim, K. S.; Hahn, S. K. Hyaluronate-gold nanoparticle/tocilizumab complex for the treatment of rheumatoid arthritis. ACS Nano 2014, 8, 4790-4798.

[93] Schulze, K.; Koch, A.; Schöpf, B.; Petri, A.; Steitz, B.; Chastellain, M.; Hofmann, M.; Hofmann, H.; von Rechenberg, B. Intraarticular application of superparamagnetic nanoparticles and their uptake by synovial membrane-An experimental study in sheep. J. Magn. Magn. Mater. 2005, 293, 419-432.

[94] Kim, J.; An, H. Y.; Rieter, W. J.; Esserman, D.; TaylorPashow, K. M. L.; Sartor, R. B.; Lin, W.; Tarrant, T. K.
Multimodal optical and Gd-based nanoparticles for imaging in inflammatory arthritis. Clin. Exp. Rheumatol. 2009, 27, 580-586.

[95] Prasad, S. R.; Elango, K.; Damayanthi, D.; Saranya, J. S. Formulation and evaluation of azathioprine loaded silver nanopartilces for the treatment of rheumatoid arthritis. Asian J. Biomed. Pharm. Sci. 2013, 3, 28-32.

[96] Ye, J. S.; Wang, Q.; Zhou, X. F.; Zhang, N. Injectable actarit-loaded solid lipid nanoparticles as passive targeting therapeutic agents for rheumatoid arthritis. Int. J. Pharm. 2008, 352, 273-279.

[97] Xue, M.; Jiang, Z.-Z.; Wu, T.; Li, J.; Zhang, L.; Zhao, Y.; Li, X.-J.; Zhang, L.-Y.; Yang, S.-Y. Anti-inflammatory effects and hepatotoxicity of Tripterygium-loaded solid lipid nanoparticles on adjuvant-induced arthritis in rats. Phytomedicine 2012, 19, 998-1006.

[98] Nagai, N.; Ito, Y. Effect of solid nanoparticle of indomethacin on therapy for rheumatoid arthritis in adjuvant-induced arthritis rat. Biolog. Pharm. Bull. 2014, 37, 1109-1118.

[99] Zhou, H.-F.; Chan, H. W.; Wickline, S. A.; Lanza, G. M.; Pham, C. T. N. $\alpha_{\mathrm{v}} \beta_{3}$-Targeted nanotherapy suppresses inflammatory arthritis in mice. FASEB J. 2009, 23, 2978-2985.

[100] Koo, O. M. Y.; Rubinstein, I.; Önyüksel, H. Actively targeted low-dose camptothecin as a safe, long-acting, disease-modifying nanomedicine for rheumatoid arthritis. Pharm. Res. 2011, 28, 776-787.

[101] Wishart, D. S.; Knox, C.; Guo, A. C.; Shrivastava, S.; Hassanali, M.; Stothard, P.; Chang, Z.; Woolsey, J. DrugBank: A comprehensive resource for in silico drug discovery and exploration. Nucleic Acids Res. 2006, 34, D668-D672.

[102] Bernstein, F. C.; Koetzle, T. F.; Williams, G. J. B.; Meyer, E. F., Jr.; Brice, M. D.; Rodgers, J. R.; Kennard, O.; Shimanouchi, T.; Tasumi, M. The Protein Data Bank: A computer-based archival file for macromolecular structures. Arch. Biochem. Biophys. 1978, 185, 584-591.

[103] Barrera, P.; Mulder, S.; Smetsers, A. I.; Storm, G.; Beijnen, J. H.; Metselaar, J. M.; van Riel, P. L. Long-circulating liposomal prednisolone versus pulse intramuscular methylprednisolone in patients with active rheumatoid arthritis. In Arthritis and Rheumatism; Wiley-Liss Div John Wiley \& Sons Inc: USA, 2008; pp 3976-3977. 